\title{
The Reconciliation Attitudes of Former Child Soldiers in Northern Uganda
}

\author{
Benjamin Alipanga ${ }^{1,2}$, Maarten De Schryver ${ }^{3}$, Stella Neema ${ }^{1}$, Eric Broekaert ${ }^{4}$ and Ilse Derluyn ${ }^{2}$ \\ ${ }^{1}$ Department of Community and Mental Health, College of Humanities and Social Sciences, Makerere University, Kampala, Uganda \\ ${ }^{2}$ Department of Social Welfare Studies and Centre for Children in Vulnerable Situations, Ghent University, Gent, Belgium \\ ${ }^{3}$ Department of Experimental Clinical and Health Psychology, Ghent University, Gent, Belgium \\ ${ }^{4}$ Department of Orthopedagogics, Ghent University, Gent, Belgium
}

*Corresponding author: Benjamin Alipanga, School of Psychology, Makerere University, P.O Box 7062, Kampala, Uganda, Tel: +256 772-360092, +32 477-816032; Email: benpanga@gmail.com

Received Date: July 8, 2014, Accepted Date: September 23, 2014, Published Date: September 30, 2014

Copyright: $\odot$ 2014, Benjamin A et al., This is an open-access article distributed under the terms of the Creative Commons Attribution License, which permits unrestricted use, distribution, and reproduction in any medium, provided the original author and source are credited.

\begin{abstract}
Introduction: While the reintegration processes of former child soldiers have been widely studied, little attention has been paid to their reconciliation attitudes, and in particular possible associations between these reconciliation attitudes and different risk factors. Therefore, this study examined reconciliation attitudes of formerly abducted adolescents living in post-conflict Northern Uganda, compared to non-conscripted youth, and possible associations with war-related stressful experiences and daily stressors.
\end{abstract}

Methods: Four hundred forty five war-affected adolescents living in Northern Uganda were included, of which $214(48.1 \%)$ were formerly abducted. All completed questionnaires on exposure to stressful war experiences (Stressful War Events Questionnaire), daily stressors (Adolescent Complex Emergency Daily Stressors Scale), and attitudes towards reconciliation (Openness to Reconciliation Questionnaire). Associations between several sociodemographics, war-related and daily stressors and reconciliation attitudes were explored using hierarchical linear regression models.

Results: Findings showed that conscripted youth experienced more stressful war experiences and daily stressors than non-conscripted youth, and that they scored higher on the different reconciliation attitudes (goodwill attitudes, positive feelings towards the future, feelings of avoidance and of revenge). Having been recruited as child soldier was associated with more revenge attitudes compared to non-abducted children, and girls showed more goodwill attitudes than boys. Above, a larger exposure to war-related and daily stressors was associated with overall higher reconciliation attitudes, although particular interaction effects showed complex relationships here.

Conclusion: Overall war-related stressors, daily stressors and, to a lesser degree, abduction status and gender are associated with reconciliation attitudes. The findings have implications for agencies working to promote postconflict recovery among war-affected children.

Keywords: Child soldiers; Reconciliation attitudes; War-related stressors; Daily stressors

\section{Introduction}

In Uganda, up till 2006, thousands of children were exposed to experiences of child soldiering. Most of them were abducted by the rebels of the Lord's Resistance Army (LRA) that had been fighting against the Ugandan government. In captivity, the children had to endure various difficult experiences related to war. These included serving as porters, sexual and domestic servants, fighting, and witnessing or committing horrific injuries on others, including mutilation and killing of civilians [1-7]. Returning home, the former child soldiers had to deal with a lot of stress on daily basis. Some of such stress concerned fact that they-forcibly-went through a range of extremely difficult experiences, hereby also having lost many things in their lives, such as education, schooling, and family life [8-10]. Moreover, back home, they often encounter a huge hostility towards them from the society in which they want to reintegrate [11]. This can be induced by, amongst other reasons, the extreme atrocities these former child soldiers (forcibly) committed against civilians, because they return with children resulting from sexual violence, or because of the psychological problems they still show [12-15].

Though many studies have looked at the reintegration processes of formerly abducted children [6,16], few studies have explored their attitudes towards reconciliation. For example Bayer, Klasen and Adam [4], believing that rebuilding war-torn societies involves understanding how psychological trauma may shape former child soldiers' ability to reconcile, investigated and found associations between posttraumatic stress disorder (PTSD) symptoms and openness to reconciliation and feelings of revenge in 169 former child soldiers (aged 11-18 years) in rehabilitation centers in Uganda and the Democratic Republic of the Congo. However, their focus was mainly on PTSD symptoms and did not explore the possible influence of stressful war-related experiences and daily stressors on the children's feelings of reconciliation. Moreover, this study didn't investigate possible differences between abducted children and their never conscripted counterparts. 
Given former child soldiers' forced nature of abduction in Northern Uganda and their horrific experiences, the losses they suffered as well as the stigmatization and exclusion they experienced upon return, the question whether or not this range of war-related traumatic events (including child soldiering) and daily stressors might impact the reconciliation attitudes they hold is still unanswered. This study therefore will examine reconciliation attitudes of former child soldiers in comparison with a group of non-conscripted youth, and possible associations between their attitudes towards reconciliation and the war-related traumatic events and daily stressors they endured and still are confronted with.

\section{Methods}

\section{Study setting and sample}

The study was approved by the Ugandan National Council for Science and Technology (UNCST), the Ethical Committee of Ghent University, and local leaders (Resident District Commissioner, subcounty chiefs, Local Council chairpersons and the head teachers of the schools involved).
Four hundred forty five adolescents, both school-going and out-ofschool youths, originating from two communities in Otuke district, Northern Uganda were included in the study. For the school-going children, the study was carried out in the secondary schools in each community $(n=2)$.In these schools, all 13- till 21-years old pupils who were available at the time of the study ( $n=286$ out of a total of about 560 students; 187 out of 400 from Adwari secondary school and 99 out 160 from Otuke secondary school) were involved. Additionally, outof-school adolescents $(n=151)$ who met the inclusion criteria (aged between 13 and 21 years and living in one of the two targeted communities) were selected. Local leaders helped to mobilize and direct possible participants to the data collection centers identified within the communities.

Of all 445 participants, 214 (48.1\%) were former child soldiers, while 231 (51.9\%) did not report having been conscripted by the LRA. The two groups differed on some socio-demographic characteristics: less former child soldiers live together with both parents, less are involved in schooling, and more often their father is deceased (table 1).

\begin{tabular}{|c|c|c|c|c|c|}
\hline & & $\begin{array}{l}\text { Total group } \\
(n=445)\end{array}$ & $\begin{array}{l}\begin{array}{l}\text { Former } \\
\text { soldiers }\end{array} \\
(n=214)\end{array}$ & $\begin{array}{l}\text { Non-abducted children } \\
(\mathrm{n}=231)\end{array}$ & ${ }^{2} / \mathrm{t}$ \\
\hline \multirow[t]{2}{*}{ Gender } & Male & $277(62.2)$ & $139(65.0)$ & $138(59.7)$ & 1.07 \\
\hline & Female & $168(37.8)$ & $75(35.0)$ & $93(40.3)$ & \\
\hline \multirow[t]{2}{*}{ Lives with } & Both parents & 222 (49.9) & $87(40.7)$ & $134(58.3)$ & $13.7^{* \star \star}$ \\
\hline & Others & $223(50.1)$ & $127(59.3)$ & $96(41.7)$ & \\
\hline \multirow[t]{2}{*}{ Educational status } & Student & $286(65.4)$ & $125(60.4)$ & $161(70.0)$ & $4.04^{*}$ \\
\hline & Non-student & $151(34.6)$ & $82(39.6)$ & $69(30.0)$ & \\
\hline \multirow[t]{2}{*}{ Father's status } & Alive & $284(63.9)$ & $112(52.6)$ & $172(74.5)$ & $22.07^{* \star \star}$ \\
\hline & Deceased & $160(36.1)$ & $101(47.4)$ & $59(25.5)$ & \\
\hline \multirow[t]{2}{*}{ Mother's status } & Alive & $353(79.7)$ & $166(77.9)$ & $188(81.3)$ & 0.62 \\
\hline & Deceased & $90(20.3)$ & $47(22.1)$ & $43(18.7)$ & \\
\hline \multirow[t]{2}{*}{ Religion } & Christian & 439 (98.9) & $210(98.1)$ & 229 (99.6) & 5.12 \\
\hline & Others & $5(1.1)$ & $4(1.9)$ & $1(0.43)$ & \\
\hline Age $^{\dagger}$ & & $17.05(1.88,13-21)$ & $17.04(1.88,14-21)$ & $17.05(1.90,13-21)$ & 0.03 \\
\hline
\end{tabular}

Table 1: Socio-demographic characteristics of abducted and non-abducted children

Four local research assistants, all trained during three days in questionnaire administration techniques, helped with administering the questionnaires. Firstly, participants were explained the study objectives, and assurance to withdraw freely at any time was given. Participants were also informed that clinical psychiatric officers from Lira Regional Referral Hospital could provide further psychological or medical support, whenever needed. Written informed consent was obtained, and thereafter, the participants completed, in small groups under supervision of the research assistants, self-report questionnaires, either in Lango or English. In case of illiterate participants, research assistants read out questionnaires aloud, and recorded the responses.

\section{Measures}

First, a series of closed questions was used to assess sociodemographic characteristics (gender, age, parent's still alive, living situation (both parents, one parent, somebody else). 
Stressful war-related experiences were assessed by the Stressful War Events questionnaire (SWE) [17], questioning 16 war-related events on a yes/no scale.

Third, daily stressors were questioned with the Adolescent Complex Emergency Daily Stressors Scale (ACEDSS) [18], asking to indicate whether or not (yes/no) they experienced 17 different daily and stigmatization-related stressors (e.g., lack of food and medical care, forced marriage, rejection by family).

Fourth, the Openness to Reconciliation Questionnaire (Adam, Unpublished habilitation, 2006) assessed the readiness for reconciliation and making peace. When completing the questionnaire, participants were instructed to think about the person or group that harmed them or their family during and/or after the war. The total score includes 33 items with four subscales: goodwill ( 8 items, e.g., 'I can sympathize with the enemy'); avoidance ( 8 items, e.g., 'I would never talk with the adversary'); revenge ( 8 items, e.g., 'I'll pay the opponents one day'); and, future orientation (9 items, e.g., 'I try to focus on the future'). The items are presented on a Likert-scale from 1 (totally incorrect) to 5 (entirely correct). For the subscales 'goodwill' and 'future orientation', higher scores indicate more positive attitudes, while for the subscales 'revenge' and 'avoidance', higher scores indicate more negative attitudes. The internal consistency of the sub-scales (Cronbach's alpha) was found to be good: goodwill: 0.79; avoidance: 0.70 ; future orientation: 0.73 ; and revenge: 0.77 .

\section{Analyses}

Differences between both groups (former child soldiers and nonabducted participants) were analyzed with $\chi^{2}$ - and independent samples t-tests. Four hierarchical linear regression models (method: enter) were carried out to analyze possible associations between a series of independent variables (socio-demographics, child soldiering experiences or not, total number of war-related traumatic events, and total number of daily stressors), and reconciliation attitudes (four subscales); the interaction effect between war-related and daily stressors was also added as independent variable. For each of the four reconciliation attitudes, a model with the demographic variables was defined as a first step; secondly, the main term war-related stressor was added; thirdly, the main term of daily stressors was added; and, finally, the interaction between war-related and daily stressors was added. The bootstrap-procedure was used to estimate standard errors as implemented in the Lavaan-package [19] to estimate the indirect and total effects when the conditions for mediation were fulfilled. To avoid multicollinearity, the variables daily stressors and war-related stressors were centered. Factors were dummy-coded. R 2.14.1 software was used to conduct all analyses [20], and alpha was set at .05.

\section{Results}

\section{War-related and daily stressors}

\begin{tabular}{|c|c|c|c|c|}
\hline & $\begin{array}{l}\text { Total group } \\
(\mathrm{n}=445)\end{array}$ & $\begin{array}{l}\text { Former child soldiers } \\
(\mathrm{n}=214)\end{array}$ & $\begin{array}{l}\text { Non-abducted children } \\
(n=231)\end{array}$ & $2 / t$ \\
\hline Death of a loved one & $404(91.2)$ & $202(94.4)$ & $202(88.2)$ & $4.53^{*}$ \\
\hline Forceful separation from family & $282(63.8)$ & $158(74.5)$ & $124(53.9)$ & $19.42^{* * *}$ \\
\hline Life in IDP camp & $320(72.7)$ & $189(89.6)$ & $131(57.1)$ & $57.18^{\star * *}$ \\
\hline Witnessing violence against others & $311(70.7)$ & $176(83.4)$ & $136(59.1)$ & $30.19^{* *}$ \\
\hline Victim of violence & $189(42.7)$ & $123(57.7)$ & $67(29)$ & $36.23^{* * *}$ \\
\hline Forced to commit violence & $165(37.4)$ & $115(54)$ & $51(22.3)$ & $46.00^{* * *}$ \\
\hline Lack of food and water & $358(80.6)$ & $185(88.9)$ & $168(72.7)$ & $18.41^{* * *}$ \\
\hline Lack of education & $342(77.4)$ & $184(86.8)$ & $158(68.7)$ & $19.84^{* * *}$ \\
\hline Lack of medical care & $378(85.5)$ & $192(90.6)$ & $187(81)$ & $7.51^{\star * *}$ \\
\hline Lack of jobs and income & $357(80.8)$ & $184(86.8)$ & $174(75.3)$ & $8.65^{* *}$ \\
\hline Wounded or disabled & $240(54.3)$ & $142(66.7)$ & $99(42.9)$ & $23.94^{* * *}$ \\
\hline Life on streets & $185(42.0)$ & $113(53.3)$ & $73(31.7)$ & $19.85^{* * *}$ \\
\hline Fear of LRA rebels & $379(85.6)$ & 201 (93.9) & $179(77.8)$ & $22.00^{* * *}$ \\
\hline Feeling of not being accepted & $258(58.1)$ & $153(71.5)$ & $106(45.8)$ & $28.90^{* * *}$ \\
\hline Responsibility for other children & $224(50.7)$ & $122(57.5)$ & $103(44.4)$ & $6.92^{* *}$ \\
\hline $\begin{array}{l}\text { Total number of stressful war } \\
\text { experiences }{ }^{\dagger}\end{array}$ & $11.41(3.11)$ & $13.36(2.93)$ & $9.46(3.40)$ & $-12.8^{* * *}$ \\
\hline \multicolumn{5}{|c|}{$\mathrm{N}(\%)$ answering "yes" to a particular item; ${ }^{\dagger}$ mean (SD) } \\
\hline
\end{tabular}

Table 2: Stressful war-related experiences of abducted and non-abducted children (SWE) 
Citation: Alipanga B, Schryver MD, Neema S, Broekaert E, Derluyn I (2014) The Reconciliation Attitudes of Former Child Soldiers in Northern

Overall, former child soldiers experienced all types of war-related stressors more frequently than non-abducted children (Table 2).

\begin{tabular}{|c|c|c|c|c|}
\hline & $\begin{array}{l}\text { Total group } \\
(\mathrm{n}=445)\end{array}$ & $\begin{array}{l}\text { Former child soldiers } \\
(n=214)\end{array}$ & $\begin{array}{l}\text { Non-abducted children } \\
(n=231)\end{array}$ & ${ }^{2} / \mathrm{t}$ \\
\hline Feeling of insecurity & $381(85.8)$ & $191(89.3)$ & $191(82.7)$ & $3.42^{*}$ \\
\hline Problems with school fees & $381(85.8)$ & $190(88.8)$ & $192(83.1)$ & 2.49 \\
\hline Inadequate food & $356(80.2)$ & $188(87.9)$ & $169(73.1)$ & $14.20^{\star * \star}$ \\
\hline Inadequate clothing & $380(85.6)$ & $195(91.1)$ & $186(80.5)$ & $9.30^{* * \star}$ \\
\hline Illness in family & $390(88.0)$ & $191(89.7)$ & $200(86.6)$ & 0.73 \\
\hline Lack of care & $359(80.9)$ & $181(84.6)$ & $179(77.5)$ & 3.17 \\
\hline Worry about family & $365(82.2)$ & $190(58.8)$ & $176(76.2)$ & $11.22^{* * *}$ \\
\hline Too much work & $320(72.4)$ & $164(77.0)$ & $156(68.1)$ & $4.19^{*}$ \\
\hline Punishment & $272(61.7)$ & $146(68.5)$ & $127(55.4)$ & $7.46^{* *}$ \\
\hline Others talking ill of you and family & $333(75.3)$ & $166(77.9)$ & $168(73)$ & 1.17 \\
\hline Discriminated against & $271(61.3)$ & $144(67.9)$ & $128(55.3)$ & $6.79^{\star *}$ \\
\hline Persecution by bad spirits & $194(43.7)$ & $110(51.4)$ & $85(36.8)$ & $9.04^{* *}$ \\
\hline Feeling abandoned by family & $171(38.5)$ & $96(44.9)$ & $75(32.6)$ & $6.70^{* *}$ \\
\hline Feeling abandoned by society & $155(35.1)$ & $87(41.0)$ & $68(29.6)$ & $6.04^{* *}$ \\
\hline Forced into marriage & $123(27.7)$ & $73(34.1)$ & $51(21.8)$ & $7.42^{* *}$ \\
\hline Do not know father & $127(28.7)$ & $68(31.9)$ & $609(25.8)$ & 1.63 \\
\hline Disagreement with family & $137(30.9)$ & $72(33.6)$ & $65(28.3)$ & 1.33 \\
\hline Total number of daily stressors ${ }^{\dagger}$ & $10.67(3.99)$ & $11.49(3.68)$ & $9.85(4.43)$ & $-4.21^{\star \star \star}$ \\
\hline
\end{tabular}

Table 3: Exposure of abducted and non-abducted children to current daily stressors (ACEDSS)

\begin{tabular}{|l|l|l|l|l|}
\hline & $\begin{array}{l}\text { Total } \\
\text { group } \\
(\mathrm{n}=445)\end{array}$ & $\begin{array}{l}\text { Former child } \\
\text { soldiers } \\
(\mathrm{n}=214)\end{array}$ & $\begin{array}{l}\text { Non-abducted } \\
\text { children } \\
(\mathrm{n}=231)\end{array}$ & $\mathbf{T}$ \\
\hline Goodwill & $\begin{array}{l}21.54 \\
(7.23)\end{array}$ & $22.46(6.72)$ & $20.71(7.57)$ & $-2.55^{*}$ \\
\hline $\begin{array}{l}\text { Future } \\
\text { orientation }\end{array}$ & $\begin{array}{l}20.05 \\
(6.82)\end{array}$ & $20.83(6.53)$ & $19.32(7.02)$ & $-2.30^{*}$ \\
\hline Avoidant & $\begin{array}{l}13.73 \\
(7.12)\end{array}$ & $14.91(7.02)$ & $12.65(7.06)$ & $-3.35^{*}$ \\
\hline Revenge & $\begin{array}{l}11.13 \\
(8.17)\end{array}$ & $12.67(8.61)$ & $9.69(7.48)$ & $-3.87^{*}$ \\
\hline $\begin{array}{l}\text { Mean (SD) } \\
{ }^{*} \mathrm{p}<.05,{ }^{* *} \mathrm{p}<.001 .\end{array}$ & \multicolumn{5}{l}{} \\
\hline
\end{tabular}

The same tendency, although less outspoken, was found for daily stressors, where former child soldiers were more often confronted with different types of daily stressors than non-abducted children (Table 3).

\section{Reconciliation attitudes}

Overall, the former child soldiers reported higher scores on the Openness to Reconciliation Questionnaire than non-conscripted participants: they showed more goodwill attitudes and more positive attitudes towards the future, and at the same time, they also reported more avoidance and revenge attitudes than non-conscripted youths (Table 4).

\section{Factors impacting reconciliation attitudes}

Table 4: Children's reconciliation attitudes (goodwill, future orientation, avoidant, and revenge attitudes) as measured by the Openness to Reconciliation Questionnaire 


\begin{tabular}{|c|c|c|c|c|c|c|c|c|c|}
\hline & \multicolumn{2}{|c|}{ Goodwill } & \multicolumn{2}{|c|}{ Future } & \multicolumn{3}{|c|}{ Avoidant } & \multicolumn{2}{|c|}{ Revenge } \\
\hline & B & $\Delta R^{2}$ & B & $\Delta R^{2}$ & \multicolumn{2}{|l|}{ B } & $\Delta R^{2}$ & B & $\Delta R^{2}$ \\
\hline Gender (ref=male) & $-1.48^{*}$ & $0.04^{\star * *}$ & -1.29 & $0.04^{* *}$ & \multicolumn{2}{|l|}{-1.16} & $0.07^{\star \star *}$ & -0.27 & $0.05^{* * *}$ \\
\hline Age & 0.27 & & 0.23 & & \multicolumn{2}{|l|}{0.31} & & 0.23 & \\
\hline Abducted (ref=yes) & 0.72 & & 0.82 & & \multicolumn{2}{|l|}{0.94} & & $2.66^{* *}$ & \\
\hline Living status(ref=other) & \multicolumn{2}{|c|}{$F(2,402)<1$} & \multicolumn{2}{|c|}{$F(2,399)<1$} & \multicolumn{3}{|c|}{$F(2,402)<1$} & \multicolumn{2}{|c|}{$F(2,406)<1$} \\
\hline Both parents & \multicolumn{2}{|l|}{0.52} & & -0.23 & & 0.36 & & -0.33 & \\
\hline One parent & \multicolumn{2}{|l|}{-0.31} & & -0.69 & & 0.48 & & 1.02 & \\
\hline War-related stressors & \multicolumn{2}{|l|}{$0.28^{*}$} & $0.02^{* *}$ & 0.19 & $0.01^{*}$ & $0.24^{*}$ & $0.04^{* \star * *}$ & -0.13 & 0.00 \\
\hline Daily stressors & \multicolumn{2}{|l|}{$0.19^{*}$} & 0.00 & 0.16 & 0.00 & $0.40^{* * *}$ & $0.04^{\star \star \star}$ & $0.50^{\star \star \star *}$ & $0.04^{* * *}$ \\
\hline War*daily stressors & \multicolumn{2}{|l|}{$0.06^{* *}$} & $0.02^{* *}$ & $0.05^{* *}$ & $0.02^{* *}$ & 0.00 & 0.00 & 0.02 & 0.00 \\
\hline
\end{tabular}

Table 5: Factors impacting reconciliation attitudes; Four hierarchical regression models (method: enter) with 'goodwill attitudes' ('goodwill'), 'positive attitudes towards the future' ('future'), 'attitudes of avoidance' ('avoidance') and 'attitudes of revenge' ('revenge') (as measured on the Openness to Reconciliation Questionnaire) as dependent variables.

Having experienced forced conscription significantly impact attitudes of revenge, with children abducted during the war reporting significantly higher scores than those who were never abducted. No significant impact of child soldiering was found on the other reconciliation subscales.

Gender was significantly associated with goodwill attitudes, with higher scores for girls than for boys. No differences were found in reconciliation attitudes related to participants' age or their living situation (with one or both parents or somebody else).

Participants who experienced a high number of war-related stressors also reported more attitudes of goodwill, although we need to take into account that there was also an interaction effect of warrelated and daily stressors in this model (cf. infra). Besides, war-related stressors also impacted attitudes of avoidance, with higher war-related stressors leading to higher scores of avoidant attitudes.

The number of daily stressors experienced showed an important impact on reconciliation attitudes: all subscales, except 'orientation towards the future', showed significant associations with the number of daily stressors (with a higher number leading to higher scores on the subscales), although for the subscale 'goodwill', we need to cautiously interpret these results, given that also an interaction effect with war-related trauma was found.

Last, for the subscales 'goodwill' and 'positive orientation towards the future', an interaction effect was found for the number of warrelated and daily stressors: A negative relation between goodwill/ future orientation and war-related stressors is observed for adolescents who experienced less daily stressors, meaning that these adolescents showed less goodwill/a more negative future orientation the more warrelated stressors they had experienced. On the other hand, adolescents who experienced a lot of daily stressors were showing more goodwill/a more positive future orientation the more war-related stressors they had experienced.

\section{Discussion}

The study examined reconciliation attitudes of Northern Ugandan former child soldiers in comparison with a group of non-conscripted youth, and assessed possible associations between these attitudes towards reconciliation, and the war-related traumatic events and daily stressors they endured and still are confronted with. Our findings indicate that former child soldiers overall showed more reconciliation attitudes, both 'positive' (a more positive orientation towards the future, more goodwill attitudes) and 'negative' (more attitudes of avoidance and revenge) in comparison to youths who were never abducted, although hierarchical regression analyses only gave evidence for higher attitudes of revenge. This latter finding can be related to the fact that these former child soldiers were abducted, so recruited against their will, which might lead to higher feelings of revenge afterwards, when being returned back home. A recent study indicated that many child soldiers in northern Uganda perceive themselves as victims [21], or people who because of past experiences of misfortune feel helpless to remedy it [22], Revenge attitudes may arise when a child is hurt and suppresses the rage [23], or may form an attempt to counteract the powerlessness, shame, and isolation possibly associated with the trauma experience [24,25], here in particular the child soldiering experiences. Feelings of revenge may also arise out of perception of unfairness [26] or when the victim is unable to mourn all losses (s)he is confronted with [27]. Further, the high levels of stigmatization - and related difficult living circumstances - former child soldiers are confronted with when returning back home [11] could also induce higher feelings of revenge. This relates to the clear association that was found between attitudes of revenge with daily stressors: the more daily stressors the adolescents experienced, the higher their revenge attitudes. The importance of the post-conflict context, and the long-lasting impact of armed conflicts onto daily living conditions are herewith clearly stressed again, now also related to its possible impact on post-conflict societal reconstruction and 
peace-building, possibly through its impact onto young people's attitudes of revenge.

Also attitudes of avoidance were associated with war-related and daily stressors. This could be related to higher levels of avoidant coping when confronted with traumatic events $[28,29]$. Above, one of the known mental health outcomes of exposure to war-related stressors is symptoms of posttraumatic stress [4], which include symptoms of avoidance. Above, daily stressors have been found to mediate the effects of war-related stressors [30] to produce posttraumatic stress reactions in victims. Since our study participants were exposed to a wide range of both war-related and daily stressors, it is not surprising that they also reported attitudes of avoidance. Above, particularly for former child soldiers, the challenges of resettling in the community after abduction may necessitate the use of avoidant attitudes as a coping method to overcome the hostile attitudes of the community [31,32].

Further, although not confirmed in the hierarchical regression analyses, we found a tendency that, next to negative reconciliation attitudes, former child soldiers also reported more positive reconciliation attitudes. Above, also for these positive reconciliation attitudes, we found high associations with war-related and daily stressors. Possible explanations for this finding could be that exposure to stressors (suffering) may lead to personal gain [33,34], raising possibilities for personal growth [35]. People might also be largely resilient in face of exposure to trauma [36,37]. Further, exposure to stressors might promote increased empathy and understanding of oneself and other people, hereby stimulating the emergence of prosocial behavior [33,34,38-44], which basis lies in positive mind state or attitudes [45]. Other studies reported that exposure to trauma motivates victims work towards prevention of future suffering $[31,46]$. Another argument is that exposure to in particular war-related stressors does not necessarily increase the level of hostility in the victims: for example Annan, Brier and Aryemo [31] and Blattman and Annan [32] found that abducted and non-abducted youth showed similar hostility levels, suggesting they still possess the ability to show positive attitudes. Further, it has been noted that with the passage of time, effects of war-related stressors lessen on their own [47], thus allowing for positive attitudes to emerge, despite adverse experiences.

The interaction of exposure to war-related and daily stressors was also associated with reconciliation attitudes. On the one hand, children reported less goodwill/more negative future orientation if they were exposed to more war-related stressors but less daily stressors. Similar findings were made among youth living in post-conflict situation [48]. On the other hand, children exposed to more daily stressors showed more goodwill/more positive future orientation if they were also exposed to more war-related stressors. Contrary to this finding, daily stressors have been found to mediate the relation between war-related stressors and psychological distress [49]. The possible influencing impact of social support, known to have a positive impact on the development of conciliatory attitudes might form an alternative explanatory hypothesis here $[49,50]$.

Last, female adolescents were more likely than males to display goodwill attitudes. One hypothesis here is that female adolescents, when faced with interpersonal relationship challenges, tend to show more coping efforts than males [51], and tend to use prosocial, assertive and empathic coping strategies [52], indicating a predisposition towards positive reconciliation attitudes under stressful situations.

\section{Implications}

The study demonstrates that reconciliation attitudes are linked with adverse experiences, including war-related and daily stressors. Efforts aiming at post-conflict recovery and overall societal post-conflict reconstruction therefore need not only to tackle directly reconciliation attitudes, but also need to impact the broader post-conflict context, reducing daily struggles and improving overall living conditions. Above, reconciliation attitudes need to be viewed in a broad spectrum of both positive and negative attitudes, which should all be addressed. Third, particular attention is needed for the huge attitudes of revenge that former child soldiers might seem to endure, through individual, familial and group counseling by integration of particular reconciliation initiatives into the counseling and psychological support. Last, more research is needed to further our understanding of these findings, through longitudinal research, and to further deepen the understanding of possible associations with other risk factors, such as mental health problems.

\section{Limitations}

The findings of this study need to be viewed in the light of the following limitations. The procedures used in the study generated selfreported data and may have introduced social desirability biases in the responses obtained. Above, we had no information about possible documented diagnoses of psychiatric illnesses in participants or about possible drug use in our study group. Moreover the sample involved in this study consisted of children living in post-conflict areas of northern Uganda, which may affect generalizability to other populations and contexts. Lastly, the study was cross-sectional, rendering it difficult to impute causal and temporal relationships among the variables involved.

\section{Acknowledgements}

We want to thank all participants.

This study was carried out with the financial support of the Belgian Technical Cooperation.

\section{References}

1. Amone-P'Lak K (2005) Psychological impact of war and sexual abuse on adolescent girls in northern Uganda. Intervention 3: 33-45.

2. Amone-P'Olak K (2006) Mental states of adolescents exposed to war in Uganda: finding appropriate methods of rehabilitation. Torture 16: 93-107.

3. Amone-P'olak K, Garnefski N, Kraaij V (2007) Adolescents caught between fires: cognitive emotion regulation in response to war experiences in Northern Uganda. J Adolesc 30: 655-669.

4. Bayer CP, Klasen F, Adam H (2007) Association of trauma and PTSD symptoms with openness to reconciliation and feelings of revenge among former Ugandan and Congolese child soldiers. JAMA 298: 555-559.

5. Dunn KC (2004) Uganda: The Lord's Resistance Army. Review of African Political Economy 31: 139-142.

6. Pham P, Vinck P, Stover E (2007) Abducted: The Lord's Resistance Army and Forced Conscription in Northern Uganda. Berkely, Tulane Initiative for Vulnerable Populations.

7. Pham PN, Vinck P, Stover E (2008) The Lord's Resistance Army and Forced Conscription in Northern Uganda. Human Rights Quarterly 30: 404-411.

8. Annan J, Blattman C, Carlson K, Mazurana D (2007) Making Reintegration Work for Youth in Northern Uganda. SWAY Appropriate Methods of Rehabilitation. Torture 16: 93-107. 
9. Bannink-Mbazzi F, Lorschiedter A (2009) Psychosocial support to vulnerable youth in vocational schools in Northern Uganda. Intervention 7: 130-137.

10. Pham PN, Vinck P, Stover E (2009) Returning home: forced conscription, reintegration, and mental health status of former abductees of the Lord's Resistance Army in northern Uganda. BMC Psychiatry 9: 23.

11. Vindevogel S, Coppens K, Derluyn I, De Schryver M, Loots G, et al. (2011) Forced conscription of children during armed conflict: experiences of former child soldiers in northern Uganda. Child Abuse Negl 35: 551-562.

12. Akello G, Reis R, Richters A (2010) Silencing distressed children in the context of war in northern Uganda: an analysis of its dynamics and its health consequences. SocSci Med 71: 213-220.

13. Corbin JN (2008) Returning home: resettlement of formerly abducted children in Northern Uganda. Disasters 32: 316-335.

14. Dickson-Gomez J (2003) Growing up in Guerilla Camps: The long term impact of being a Child Soldier in El Savador's Civil War. American Anthropological Association. Ethos 30: 327-356.

15. Stott K (2009) Out of sight, out of mind? The psychosocial needs of children formerly associated with armed forces: a case study of Save the Children UK's work in Beni and Lubero territories, North Kivu province, Democratic Republic of Congo. International journal of health planning and management 24: S52-S72.

16. Betancourt TS, Borisova II, Williams TP, Brennan RT, Whitfield TH, et al. (2010) Sierra Leone's former child soldiers: a follow-up study of psychosocial adjustment and community reintegration. Child Dev 81: 1077-1095.

17. Derluyn I, Mels C, Broekaert E (2009) Mental health problems in separated refugee adolescents. J Adolesc Health 44: 291-297.

18. Mels C, Derluyn I, Broekaert E, Rosseel Y (2010) The psychological impact of forced displacement and related risk factors on Eastern Congolese adolescents affected by war. J Child Psychol Psychiatry 51: 1096-1104.

19. Rosseel Y (2012) Lavaan: An R Package for Structural Equation Modeling. Journal of Statistical Software 48: 1-36. URL.

20. Dean CB, Nielsen JD (2007) Generalized linear mixed models: a review and some extensions. Lifetime Data Anal 13: 497-512.

21. Klasen F, Reissmann S, Voss C, Okello J (2014) The Guiltless Guilty: Trauma-Related Guilt and Psychopathology in Former Ugandan Child Soldiers. Child Psychiatry Hum Dev .

22. Landau SI (2000). Encarta World English Dictionary, and: Microsoft Encarta World English Dictionary (review). Dictionaries: Journal of the Dictionary Society of North America 21, 1: 112-124.

23. Hardy KV, Laszloffy TA (2005) Teens who hurt: Clinical interventions to break the cycle of violence, Guilford, New York.

24. LaFarge L (2006) The wish for revenge. Psychoanal Q 75: 447-475.

25. Horowitz MJ (2007) Understanding and ameliorating revenge fantasies in psychotherapy. Am J Psychiatry 164: 24-27.

26. De Cremer D (2006) Unfair Treatment and Revenge Taking: The Roles of Collective Identification and Feelings of Disappointment. Group Dynamics: Theory, Research, and Practice 10: 220-232.

27. Thomas NK (2004) An eye for an eye: Fantasies of revenge in the aftermath of trauma. In D. Knafo (Ed.), Living with terror, working with trauma: A clinician's handbook (pp. 297-311). Lanham, MD: Rowan \& Littlefield.

28. Bal S, Van Oost P, De Bourdeaudhuij I, Crombez G (2003) Avoidant coping as a mediator between self-reported sexual abuse and stressrelated symptoms in adolescents. Child Abuse Negl 27: 883-897.

29. Thabet AA, Tischler V, Vostanis P (2004) Maltreatment and coping strategies among male adolescents living in the Gaza Strip. Child Abuse Negl 28: 77-91.
30. Rasmussen A, Nguyen L, Wilkinson J, Vundla S, Raghavan S, et al. (2010) Rates and impact of trauma and current stressors among Darfuri refugees in Eastern Chad. Am J Orthopsychiatry 80: 227-236.

31. Annan J, Brier M, Aryemo F (2009) "From 'Rebel' to 'Returnee': The Reintegration of Young Soldiers in Northern Uganda." Journal of Adolescent Research 24: 639-667.

32. Blattman C, Annan J (2010) The Consequences of Child Soldiering. The Review of Economics and Statistics 92: 882-898.

33. Linley PA (2003) Positive adaptation to trauma: wisdom as both process and outcome. J Trauma Stress 16: 601-610.

34. Tedeschi RG, Calhoun LG (2004) Post-traumatic growth: Conceptual foundations and empirical evidence. Psychological Inquiry 15: 1-18.

35. Linley PA, Joseph S (2004) Positive change following trauma and adversity: a review. J Trauma Stress 17: 11-21.

36. Bonanno GA (2004) Loss, trauma, and human resilience: have we underestimated the human capacity to thrive after extremely aversive events? Am Psychol 59: 20-28.

37. Waysman M, Schwarzwald J, Solomon Z (2001) Hardiness: an examination of its relationship with positive and negative long term changes following trauma. J Trauma Stress 14: 531-548.

38. Calhoun LG, Tedeschi RG (2004) The foundations of posttraumatic growth. Psychological Inquiry 15: 93-102.39.

39. Frazier P, Greer C, Gabrielsen S, Tennen H, Park C, et al. (2013) The relations between trauma exposure and prosocialbehavior. Psychological Trauma. Theory, Research, Practice, and Policy 5: 286-294.

40. Lutha SS, Cicchetti D (2000) The construct of resilience: implications for interventions and social policies. DevPsychopathol 12: 857-885.

41. Shaw A, Joseph S, Linley PA (2005) Religion, spirituality and posttraumatic growth: A systematic review. Mental Health, Religion, and Culture 8: 1-11.

42. Staub E, Vollhardt J (2008) Altruism born of suffering: the roots of caring and helping after victimization and other trauma. Am J Orthopsychiatry 78: 267-280.

43. Tedeschi RG, Calhoun LG,Cann A (2007) Evaluating resource gain: Understanding and misunderstanding posttraumatic growth. Applied Psychology. An International Review 56: 396-407.

44. Vollhardt JR (2009). Altruism born suffering and prosocial behavior following adverse life events: A review and conceptualization. Social Justice Research 22: 53-97.45.

45. Almeida DM, Kessler RC (1998) Everyday stressors and gender differences in daily distress. J PersSocPsychol 75: 670-680.

46. Lifon RJ (2003) "In the Lord's hands". America's apocalyptic mindset. World Policy Journal 20: 59.

47. Thabet AA, Vostanis P (2000) Post traumatic stress disorder reactions in children of war: a longitudinal study. Child Abuse Negl 24: 291-298.

48. Lavi T, Solomon Z (2005) Palestinian Youth of the Intifada: PTSD and Future Orientation. J Am Acad Child Adolesc. Psychiatry 44:11.

49. Orientation. Journal of American Academy of Child \& Adolescence Psychiatry 44: 1176-1183.Fernando GA, Miller KE, Berger DE (2010) Growing Pains: The Impact of Disaster-Related and Daily Stressors on the Psychological and Psychosocial Functioning of Youth in Sri Lanka, Claremont Graduate University. Child Development 81: 1192-1210.

50. Annan J, Blattman C, Horton R (2006) The State of Youth and Youth Protection in Northern Uganda; Findings from the Survey for War Affected Youth. A Report for UNICEF Uganda.

51. Santacana MF, Kirchner T, Abad J, Amador JA (2012) Differences between genders in coping: Different coping strategies or different stressors? Anuario de Psicología 42: 5-18.

52. Renk K, Creasey G (2003) The relationship of gender, gender identity, and coping strategies in late adolescents. J Adolesc 26: 159-168. 